\title{
Dendritic reidite from the Chesapeake Bay impact horizon, Ocean Drilling Program Site 1073 (offshore northeastern USA): a fingerprint of distal ejecta?
}

\author{
Aaron J. Cavosie', Marc B. Biren², Kip V. Hodges², Jo-Anne Wartho³, J. Wright Horton \\ $\mathrm{Jr}^{4}$, , Christian Koeberl ${ }^{5}$ \\ ${ }^{1}$ Space Science and Technology Centre and The Institute for Geoscience Research (TIGeR), \\ School of Earth and Planetary Science, Curtin University, Perth, WA 6102, Australia \\ ${ }^{2}$ School of Earth and Space Exploration, Arizona State University, Tempe AZ 85287, USA \\ ${ }^{3}$ GEOMAR Helmholtz Centre for Ocean Research Kiel, 24148 Kiel, Germany \\ ${ }^{4}$ U.S. Geological Survey, 926A National Center, Reston, Virginia 20192, USA \\ ${ }^{5}$ Department of Lithospheric Research, University of Vienna, Althanstrasse 14, A-19090 Vienna, \\ Austria
}

\section{Item DR1 contains:}

- Sample information.

- $\quad$ Figure S1. EBSD orientation maps.

- Figure 22. Pole figures.

- Additional information on EBSD methods.

- References cited.

\section{Sample information}

The grain analyzed in this study was briefly mentioned in a previous (U-Th)/He thermochronology study on zircon grains from Chesapeake Bay impact ejecta. Interested readers should see Biren et al. (2019), and a short summary is provided here. The sample that yielded the reidite grain is from ODP Leg 174A, site 1073, Hole A, core 72X, section 4, interval 83-94 cm. This site is located approximately $390 \mathrm{~km}$ from the center of the Chesapeake Bay impact structure, and is interpreted as distal impact ejecta. The sample is described as ' $\ldots \mathrm{a} \sim 30 \mathrm{~cm}^{3}$ core sample of upper Eocene unconsolidated glauconite-bearing sediment'. Further details on sample processing are provided in Biren et al. (2019).

Biren et al. (2019) conducted optical imaging and SEM imaging (secondary electron and BSE) imaging of the grain (see Biren et al., 2019, Fig. 5D). The grain was described as 'cloudy', and planar features were noted on the surface of the grain, which were interpreted as "planar deformation features'. At this stage, the presence of reidite in the studied grain had not been detected. It is also important to note that the zircon grains from the sample studied by Biren et al. (2019) contained a mixture of unshocked, shocked, and partially dissociated grains. 


\section{Electron backscatter diffraction (EBSD) maps and data}

Figure S1. EBSD maps. A: Band contrast map. Dark regions within the grain include grain boundaries, cracks, and areas that did not index well. Dark areas outside the boundary of the grain are epoxy resin. B: Phase map. C: Inverse pole figure map for reidite only. Orientations for reidite are shown in color (see legend); zircon (grey) orientations are not shown for clarity. D: Texture component (TC) map for zircon only (grey areas are reidite).
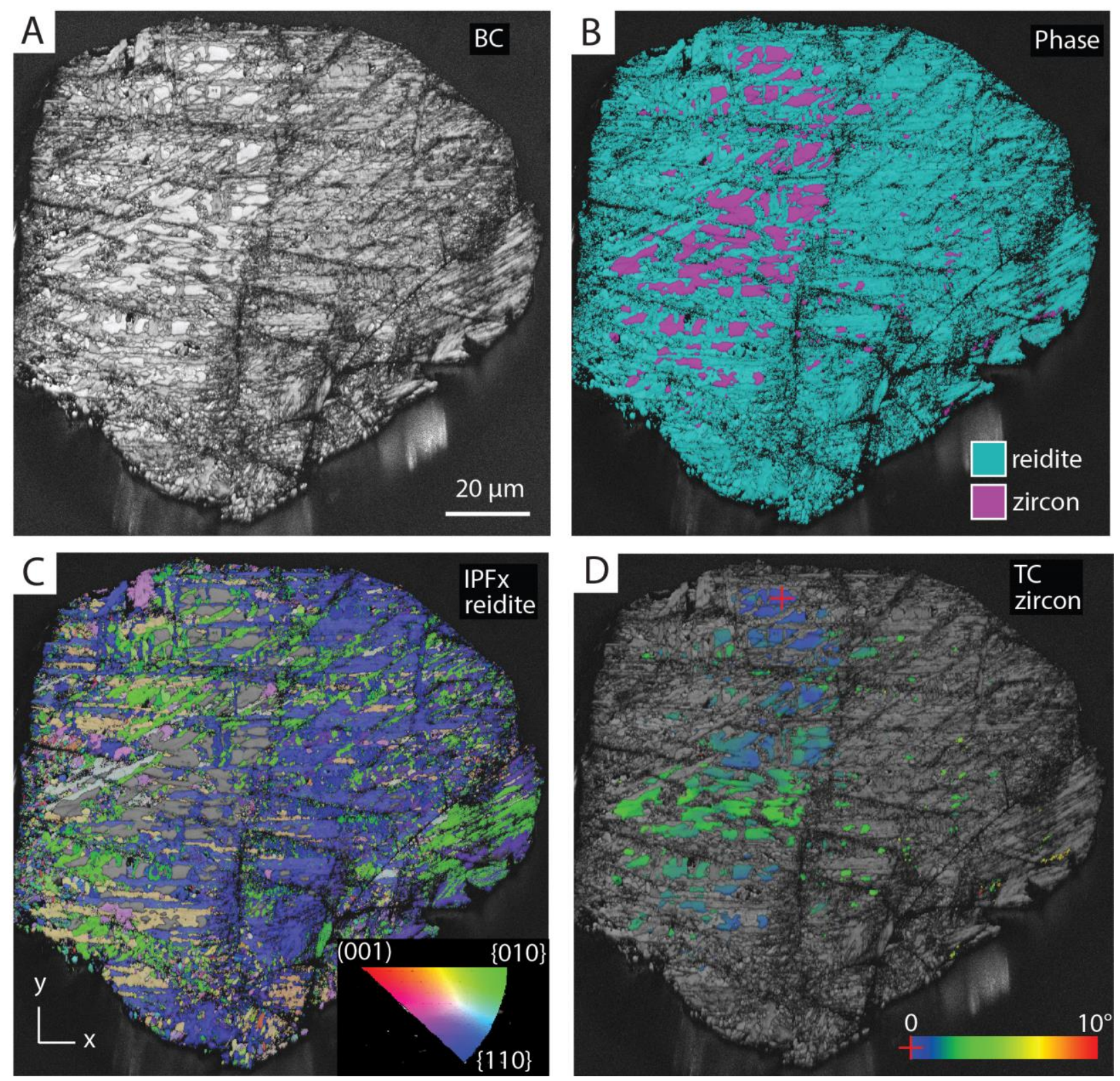
Figure S2. Pole figures. A: Pole figures for zircon. B: Pole figures for reidite. C: Combined pole figures for zircon and reidite. All are equal area, lower hemisphere projections, in the same reference frame as the IPF map above.

A. Pole figures (above) and gradient contours (below) for the remnant zircon. These plots include $99.2 \%$ of all zircon data ( $181,300 \mathrm{pts})$. Contour half width: $10^{\circ}$. Multiples of Uniform Density (MUD) ranges from 0 (blue) to 170 (red).

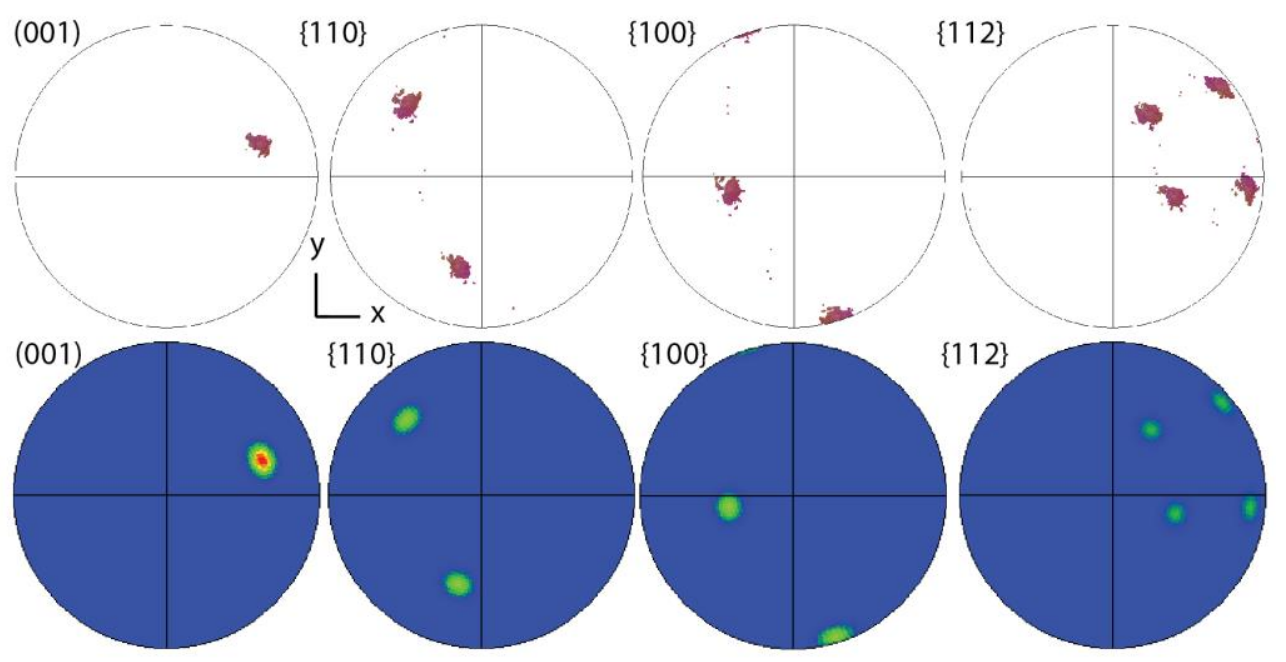

B. Pole figures (above) and line contours (below) for reidite. These plots include $100 \%$ of all reidite data $(1,406,206 \mathrm{pts})$. $\mathrm{R} 1$ and $\mathrm{R} 2$ are the two main orientations of reidite. Contour half width: $2^{\circ}$. Multiples of Uniform Density (MUD) ranges from 0 to 492.

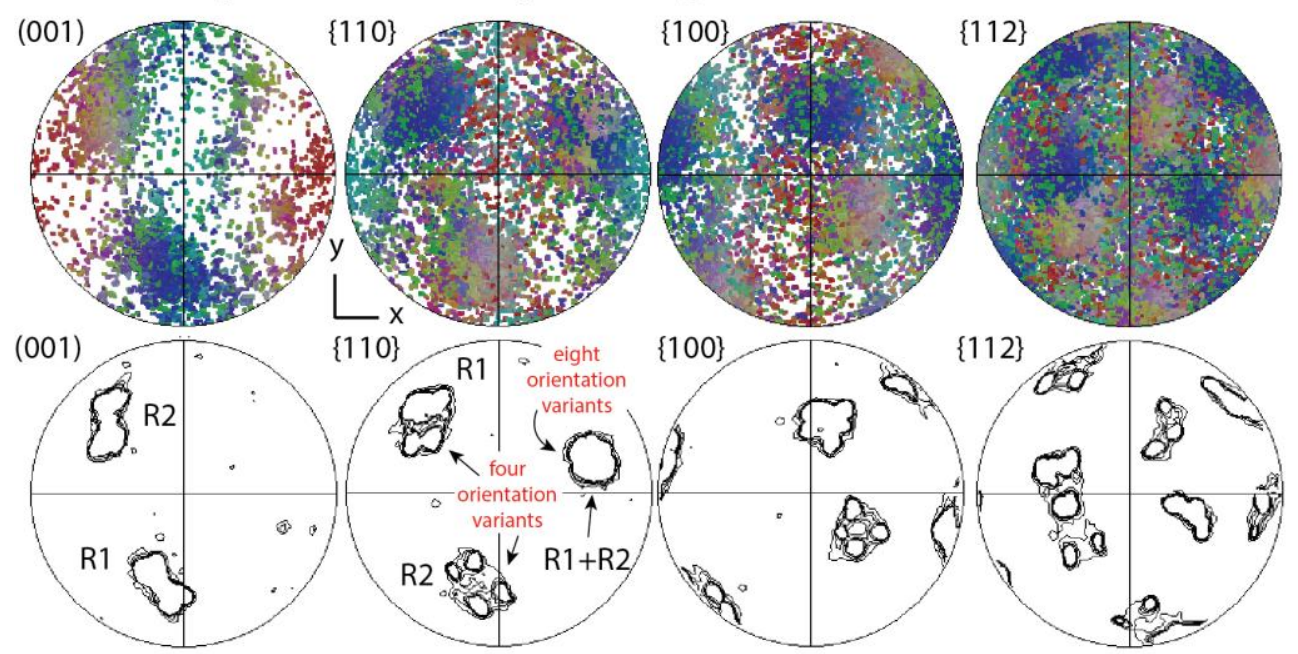

C. Combined pole figures (contoured) for zircon and reidite (from $\mathbf{A}$ and $\mathbf{B}$. above).

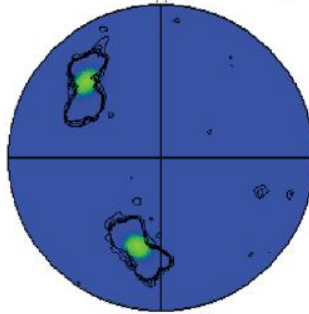

(001) reidite

$\{110\}$ zircon

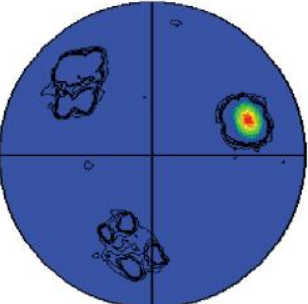

$\{110\}$ reidite

(001) zircon

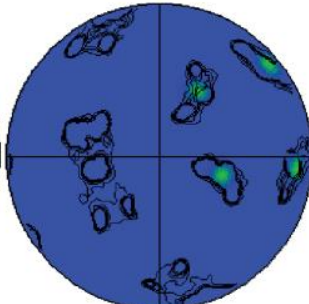

$\{112\}$ reidite

$\{112\}$ zircon

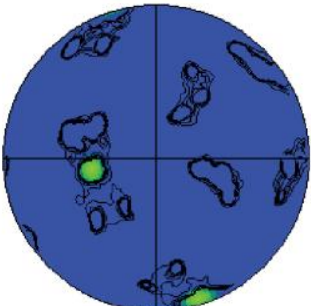

$\{112\}$ reidite $\{100\}$ zircon 


\section{Additional information on methods}

For this study, the grain was mounted in epoxy resin and ground and polished to expose the interior (core region) of the grain. Scanning electron microscopy (SEM) analysis was conducted using a Tescan MIRA3 field emission gun (FEG) SEM at the Curtin University Microscopy and Microanalysis Facility in the John de Laeter Centre. The FEG-SEM was used for BSE, CL, and EBSD imaging and analysis. The CL images were collected with a Tescan panchromatic CL detector (185-850 nm wavelength) using a $15 \mathrm{kV}$ accelerating voltage and a working distance of $16 \mathrm{~mm}$. EBSD mapping was made by indexing electron backscatter diffraction patterns over the polished section. The EBSD data were collected using a step size of $50 \mathrm{~nm}$, a $20 \mathrm{kV}$ accelerating voltage, $70^{\circ}$ sample tilt, $\sim 25 \mathrm{~mm}$ working distance, and 1-2 $\mathrm{nA}$ beam intensity. Electron backscatter patterns were collected with an Oxford Symmetry camera and Oxford Instruments AZtec system (version 4.2), using routine data acquisition and noise reduction settings (see examples of recent applications to zircon in Cavosie et al., 2018a,b). EBSD maps and pole figures were processed using the Tango and Mambo modules in the Oxford Instruments/HKL Channel 5 software package (version 5.12). The EBSD map collected here included match units for zircon (zircon5260, Mincryst database card 5260, $1 \mathrm{~atm}$; Hazen and Finger, 1979), and reidite (Reidite6032, 0.69 GPa; Farnan et al., 2003); no other phases were detected. The only noise reduction method applied was the 'wildspike' in Tango. After the wildspike procedure, 1,406,206 points remained for reidite (88.6\% of total), and 181,300 points remained for zircon (11.4\% of total). Inverse pole figure maps are color-coded to show orientation as a function of crystallography (Miller index). Pole figures for relevant planes in zircon and reidite were plotted as lower hemisphere equal area plots with the same $\mathrm{x}-\mathrm{y}-\mathrm{z}$ reference frame as the EBSD maps.

\section{References cited in the Data Repository}

Biren, M.B., Wartho, J-A., van Soest, M.C., Hodges, K.V., Cathey, H., Glass, B.P., Koeberl, C., Horton, J.W., and Hale, W., 2019, (U-Th)/He zircon dating of Chesapeake Bay distal impact ejecta from ODP site 1073: Meteoritics and Planetary Science, v. 54, p. 1840-1852. doi:10.1111/maps.13316.

Cavosie, A.J., Timms, N.E., Ferrière, L, and Rochette, P., 2018a, FRIGN zircon- The only terrestrial mineral diagnostic of high-pressure and high-temperature shock deformation: Geology, v. 46, p. 891-894, doi.org/10.1130/G45079.1.

Cavosie, A.J., Timms, N.E., Erickson, T.M., and Koeberl, C., 2018b, New clues from Earth's most elusive impact crater: Evidence of reidite in Australasian tektites from Thailand: Geology, v. 46, p. 203-206. doi.org/10.1130/G39711.1.

Farnan, I., Balan, E., Pickard, C.J., and Mauri, F., 2003, The effect of radiation damage on local structure in the crystalline fraction of $\mathrm{ZrSiO}_{4}$ : investigating the ${ }^{29} \mathrm{Si}$ NMR response to pressure in zircon and reidite: American Mineralogist, v. 88, p. 1663-1667. doi.org/10.2138/am-2003-11/1205.

Hazen, R.M., and Finger, L.W., 1979, Crystal structure and compressibility of zircon at high pressure: American Mineralogist, v. 64, p. 196-201. 